\title{
A nationwide biotechnology outreach and awareness program for Malaysian high schools
}

Mohd. Firdaus-Raih

School of BioSciences and Biotechnology

Faculty of Science and Technology

Universiti Kebangsaan Malaysia

43600 UKM Bangi, Malaysia

E-mail: mfirr@cgat.ukm.my

\section{Sahidan Senafi}

School of BioSciences and Biotechnology

Faculty of Science and Technology

Universiti Kebangsaan Malaysia

43600 UKM Bangi, Malaysia

E-mail: sahidan@pkrisc.cc.ukm.my

\author{
Abdul Munir Murad \\ School of BioSciences and Biotechnology \\ Faculty of Science and Technology \\ Universiti Kebangsaan Malaysia \\ 43600 UKM Bangi, Malaysia \\ E-mail: munir@pkrisc.cc.ukm.my

\section{Nik Marzuki Sidik} \\ School of BioSciences and Biotechnology \\ Faculty of Science and Technology \\ Universiti Kebangsaan Malaysia \\ 43600 UKM Bangi, Malaysia \\ E-mail: nms@pkrisc.cc.ukm.my

\section{Wan Kiew Lian} \\ School of BioSciences and Biotechnology \\ Faculty of Science and Technology \\ Universiti Kebangsaan Malaysia \\ 43600 UKM Bangi, Malaysia \\ E-mail: klwan@pkrisc.cc.ukm.my

\section{Fauzi Daud} \\ School of BioSciences and Biotechnology \\ Faculty of Science and Technology \\ Universiti Kebangsaan Malaysia \\ 43600 UKM Bangi, Malaysia
}

Shahrul Hisham Zainal Ariffin School of BioSciences and Biotechnology Faculty of Science and Technology Universiti Kebangsaan Malaysia 43600 UKM Bangi, Malaysia E-mail: hisham@cgat.ukm.my

\section{Zulkeflie Zamrod}

Centre for Gene Analysis and Technology School of BioSciences and Biotechnology Faculty of Science and Technology Universiti Kebangsaan Malaysia 43600 UKM Bangi, Malaysia E-mail: zza@pkrisc.cc.ukm.my

\section{Tan Chon Seng}

Malaysian Agricultural Research Development Institute

P.O. Box 12301 General Post Office

50774, Kuala Lumpur

Email: cstan@mardi.my 


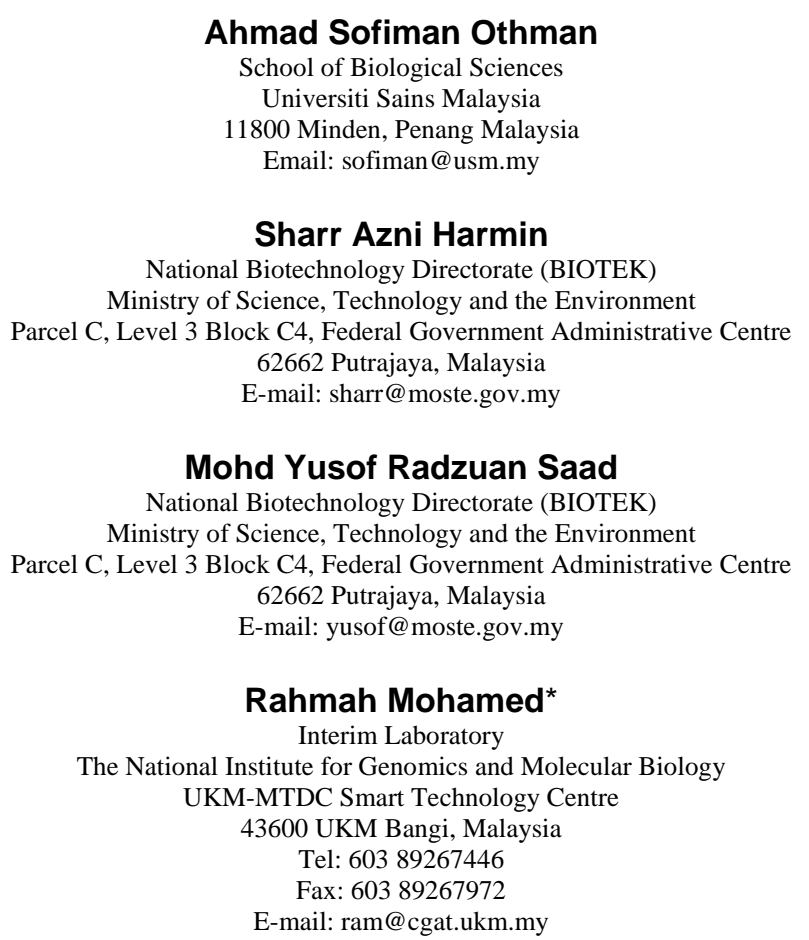

Financial support: The funds for the program described were primarily acquired form the Ministry of Science, Technology and Innovation, Malaysia, with some materiel support from the British Council (Malaysia).

Keywords: Biotechnology awareness, biotechnology education, capacity building.

Biotechnology education in developing nations remains one of the rate limiting factors in achieving optimal human resource capacity to drive and tap the bioresources of these nations. Many developing countries are situated within rich bio-diversity enclaves. Biotechnology offers the promise of tapping these bio resources towards due process of developing these nations. While there may be a steady stream of biology and biotechnology based graduates, from Malaysian as well as foreign universities contributing to the human resource base for these countries, the numbers and knowledge diversity produced, still lack the capacity to optimally power research and development as well as supply the industrial biotechnology sectors of these countries. Realizing the need to address these issues at the grassroots level of higher education, Malaysia has taken an active step of bringing biotechnology into the classrooms of high schools throughout the country. These future generations of Malaysians, are hoped to progress towards manning and driving Malaysia's BioValley initiatives (a biotech based R\&D and industry cluster), towards the national dream of developed nation status by the year 2020, using biotechnology as an economic growth vehicle. Here, we share our experiences in developing and proliferating a biotechnology awareness program for Malaysian high schools. It is hoped that similar programs will strive towards similar objectives in other developing countries.

Biotechnology education is a broad field. Public education in modern biotechnology is a difficult and complicated endeavour. When biotechnology is discussed, usually two very different but interrelated areas come into context. On one hand, there is what can be termed as classical biotechnology, which covers activities such as fermentation and breeding by genetic selection, as two common examples. On the other hand is modern biotechnology, which takes into account the molecular systems that are involved in biology and these, will primarily cover recombinant DNA technology and its applications. Classical biotechnology may have been around for thousands of years but is still relevant in this day and age of

\footnotetext{
* Corresponding author
} 
the post genomics era. Together, both technologies can work hand in hand, to provide a better quality of life for current and future generations. This is even truer in developing nations. Many of these countries still suffer from undernourishment and a low quality of life in comparison to populations of developed nations. In many developing countries, biotechnology has become a source of economic development and social progress (DaSilva, 1998).

Malaysia needs to address a number of issues with regard to biotechnology development. While the country is gifted with a rich, almost untapped resource in the form of her biodiversity, the diverse range of human resource required for a biotechnology industry, is only slowly falling in place.
The policy makers are faced with the problem of responsibly educating the Malaysian public, while at the same time seeding the grassroots with the prospects of careers in biotechnology research and industry. It was deemed that one feasible and effective way of doing this was by embarking on a biotechnology awareness program targeted at students of Malaysian high schools. This decision was made considering that the final years of high school is usually a time when students start thinking about true career directions as opposed to just childhood dreams. This age range was also selected when taking into account the maturity of the students, to begin comprehending modern biotechnology, and at the same time, this age range was also deemed suitable as students of this age group are generally vocal and critical enough to disperse the

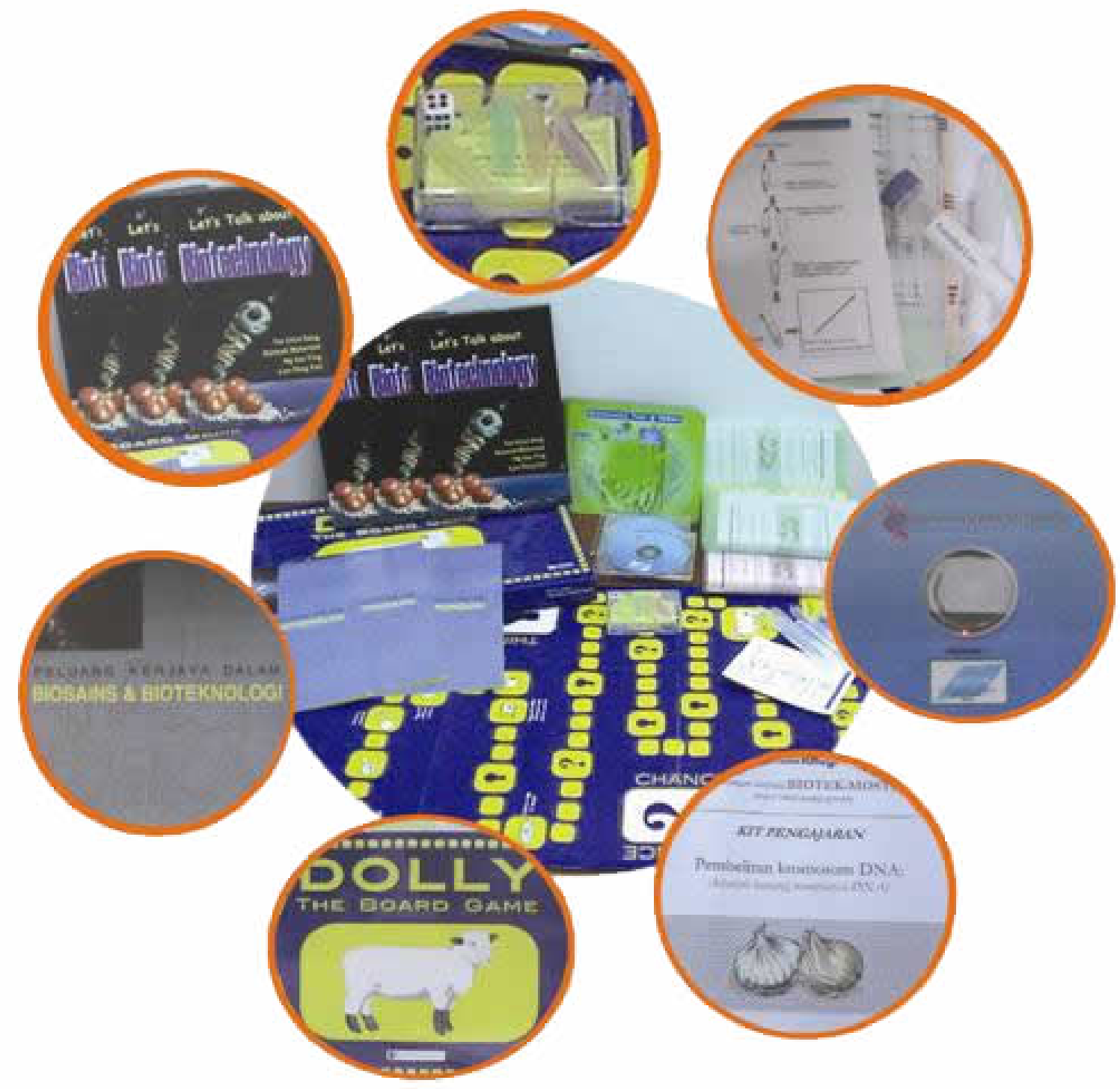

Figure 1. Montage of the kits and logistics which are distributed to the participating schools including career guidance pamphlets, games, DNA extraction kits (for onion chromosomal DNA), CDs and literature packages. 
information to their peers as well as other family members.
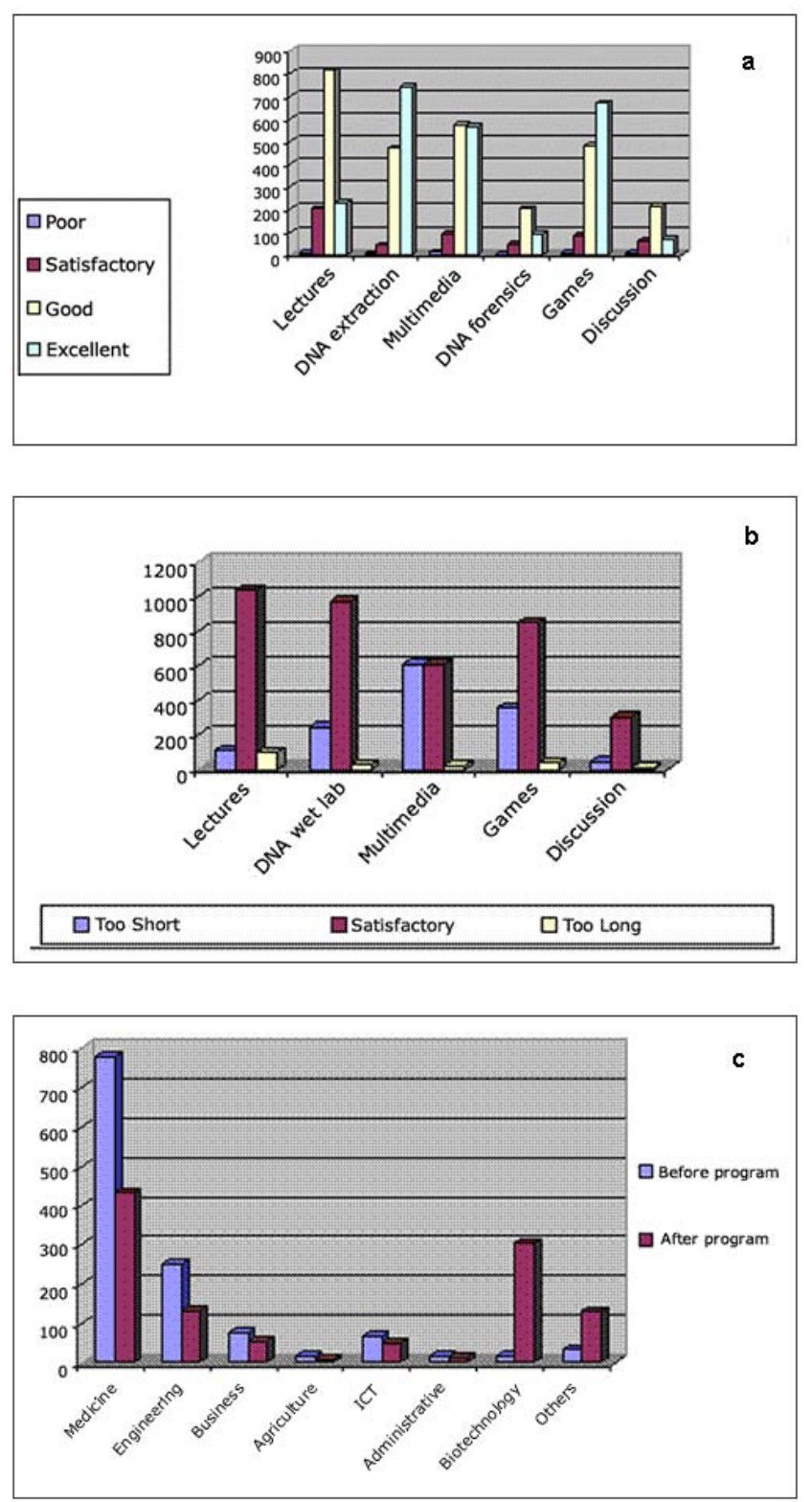

Figure 2. Results of surveys taken after each school visit for 2003 covering approximately 6000 students:

(a) Feedback on quality and suitability of the program content;

(b) Feedback on the suitability of the time frame allocated for the various sessions during each school visit;

(c) Feedback on career choices by referring to the information disbursed during the sessions and was found to have affected the choices of a healthy ratio of the students; ICT is an abbreviation for 'Information and Communications Technology'. There were respondents which did not fully complete the survey sheets distributed.

It was hoped that this approach would educate and create an awareness of what biotechnology is all about; its promises, its applications as well as how it will affect our daily lives at present and in the future. While the target group of the program may be considered as small when compared to the total Malaysian population, it is hoped that continuously, this program will have an impact at national level by sowing the seeds towards creating a credible biotech workforce and an educated biotech consumer base. At the same time, interactions of the target students with other direct members of their community such as peers and family members will at the same time create an awareness of biotechnology within a secondary target group. Another point of importance to note is that, the program was not created as a 'pro' biotechnology program, but was tailored as a biotechnology awareness program. Therefore, the dangers that could arise from GMOs, biological warfare and other similarly negative aspects were also inserted as stabilizing elements towards educating the students that biotechnology, as many other beneficial technologies, is also a double edged sword.

\section{PROGRAM CONTENT}

The Malaysian High Schools Biotechnology Awareness Program was successfully initiated in 2001. This involved road shows with teams of facilitators, comprised of university academics and scientists from Malaysian research institutes, travelling from school to school. This approach was selected to put the participants and facilitators at ease with each other and therefore providing a conducive environment where high school students, university professors, academicians, postgraduates, research scientists and science teachers could all interact in a friendly and relaxed atmosphere. The selected schools were either approached for the program directly or schools which had heard of the program and had volunteered their participation. During the process of selecting the schools, emphasis was also given to schools located in rural areas.

The primary problem that faced the program was in developing a uniform program content involving multiple teams carrying out the same routines simultaneously at different schools. As an answer to this problem, a syllabus was created and the modus operandi and logistics of each road show was centrally coordinated (Figure 1). It was deemed more effective in terms of human resource utilization as well as outreach capability when the program is proliferated by many teams operating along a uniform doctrine. Operationally, the road shows were divided into two major sessions; one session consisted of a series of talks, lectures and discussions; while the other session consisted of three different hands-on sub-sessions. The three hands-on sub-sessions are games, wet-lab hands on and multimedia self exploration with a fun quiz (Figure 2a; Figure 2b; Figure 3). From the feedback that was received, the majority of participants found that the content of the 


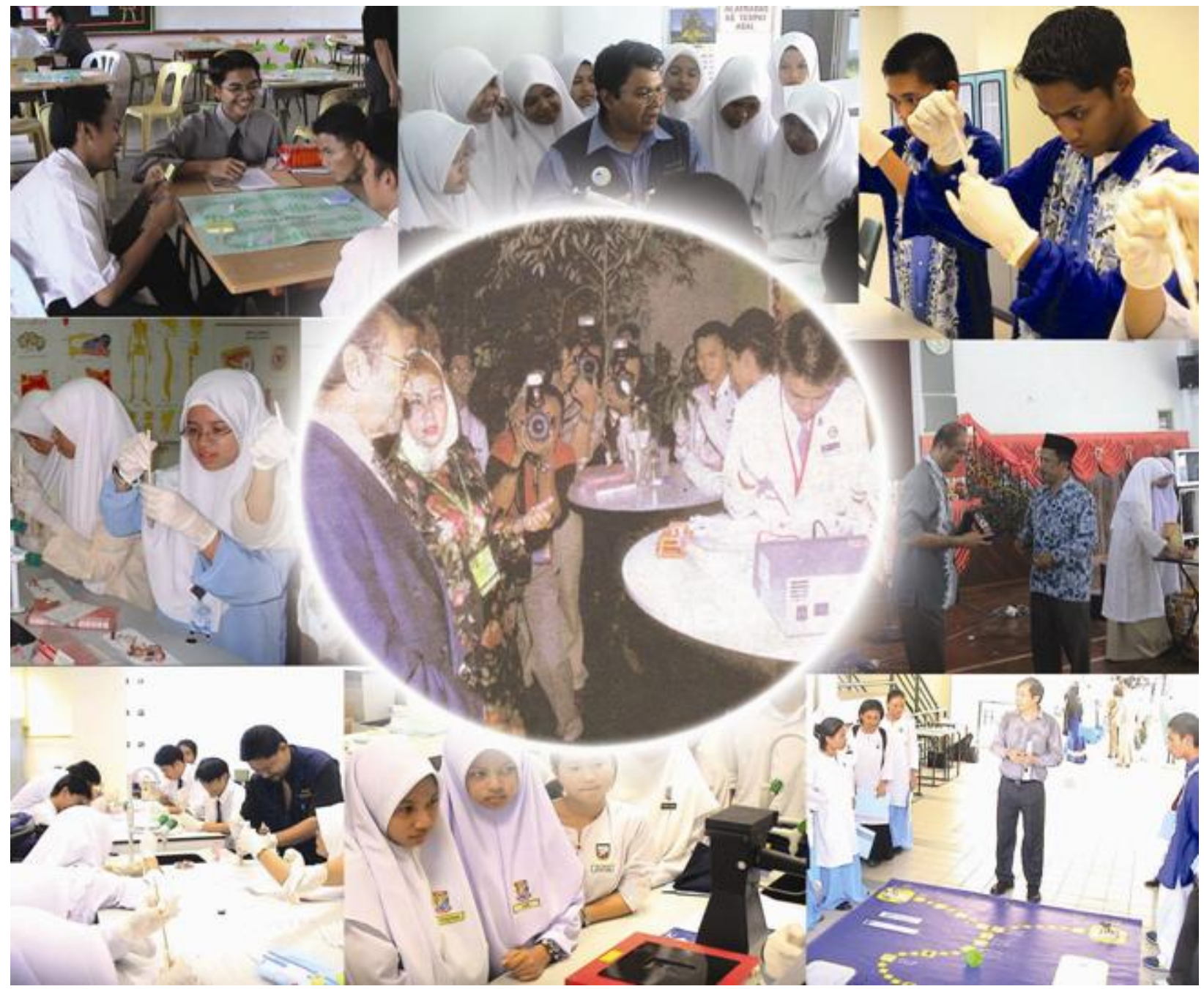

Figure 3. A montage of the activities carried out in the Malaysian High Schools Biotechnology Awareness program and serves to illustrate the interaction that was achieved by practicing scientists, senior academics and the target high school students during the course of the sessions. The central insert shows the Hon. Dr. Mahathir Mohammad, former Primer Minister of Malaysia, observing the students extracting chromosomal DNA from onions.

sessions were either good or excellent and the time that was allocated for each session was satisfactory (Figure 2b).

The talks, lectures and discussions served as an introduction to the syllabus of the program. The topics of the opening lectures and discussions centre around an introduction to biotechnology, its diverse applications and hot topics - such as cloning, the human genome project. The lectures and discussion then proceed to allow a more participative role for the audience with topics such as biotechnology careers, post high school routes and options towards embarking on a biotechnology based career. In Malaysian society, families are still locked in a conventional mindset when it comes to defining careers deemed as successful. This sort of thinking is expressed upon the children when it comes to career choices. The majority will mention physicians (doctors), engineers, accountants or lawyers as their choice of occupation. However, there still needs to be more adventurism to explore newer fields which promise just as much success, such as software engineering and up to an extent biotechnology. The speakers during this session will try to impress on the students these alternatives. Another point that the speakers try to get across is the diversity of biotechnology. The participants are made to comprehend that, to embark on a career in biotechnology, one need not be a molecular biologist or have a primarily biology trained background. They are shown the true composition of skills and knowledge which make modern biotechnology an almost seamless multidisciplinary endeavour, which requires engineers, mathematicians, physicists, chemists and computer scientists, to name a few, who work with biologists in making modern biotech research and industry tick. From a survey which are carried out at the end of the 
session at each school, we are pleased to note that a healthy ratio from the total have switched their original career choice by considering biotechnology and 'other' careers as a choice (Figure 2c). We view as a partial success of the program to open up the student's minds to other career prospects either directly in biotechnology or those that are supporting biotechnology.

The wet-lab hands on sessions consist of students carrying out activities such as extraction of chromosomal DNA from onions, agarose gel electrophoresis of nucleic acids, restriction digestion of genomic DNA (Restriction Fragment Length Polymorphism - RFLP) and introductory
PCR (Polymerase Chain Reaction) (Figure 3). In these sessions the students are exposed to many basic procedures in a molecular biology laboratory. The resources required are minimal and can usually be obtained from a high school lab or the kitchen. Chemicals, reagents and equipment such as agarose, restriction enzymes and electrophoresis sets are provided by the facilitators. These are funded by the Ministry of Science, Technology and Innovation. The main purpose of these hands on activities was to simply demonstrate that all living organisms carried molecular genetic material (nucleic acids) which can be extracted and analyzed. These sessions also include discussions as to how the genetic material could be used for differentiation

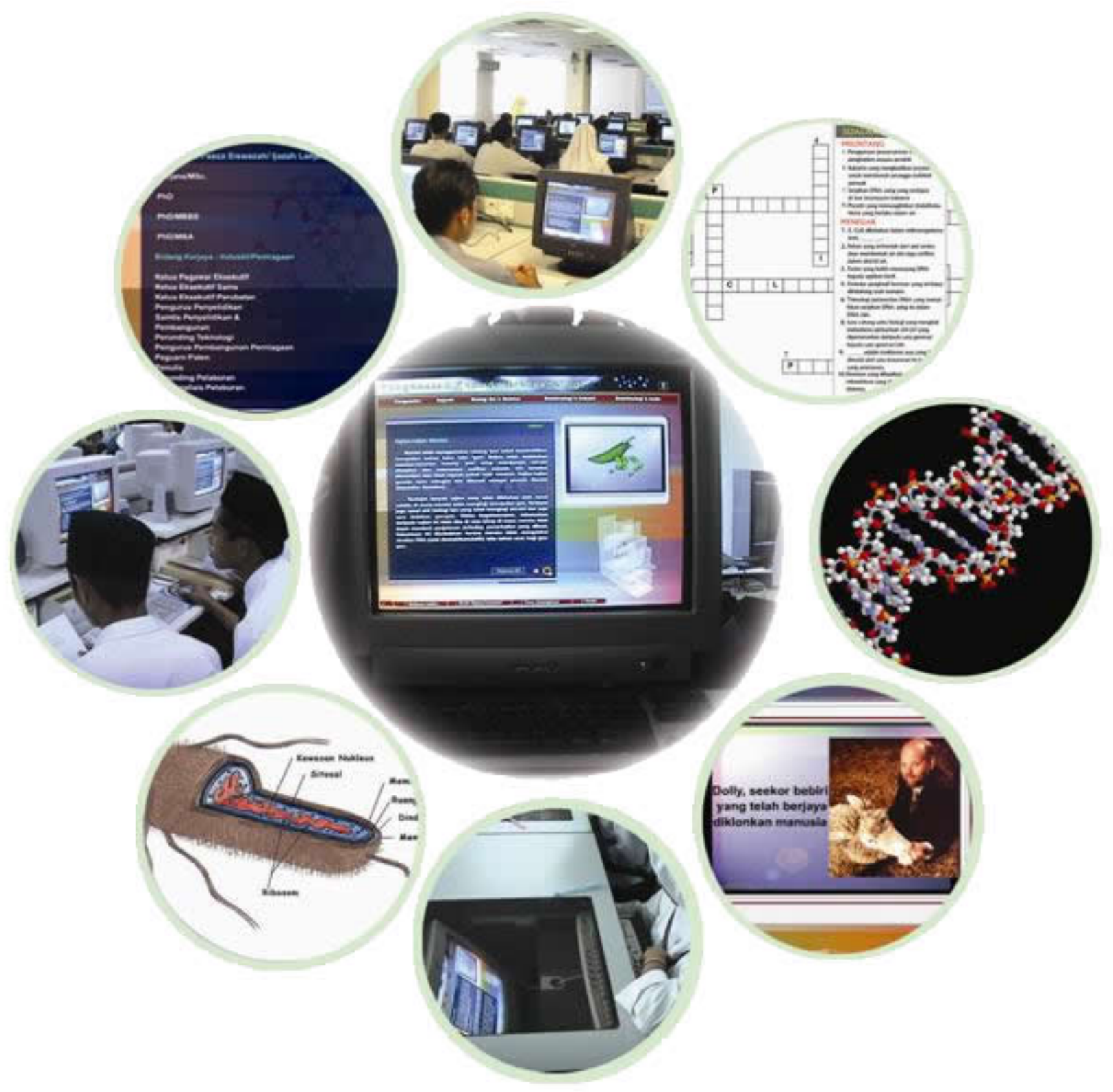

Figure 4. A montage of the multimedia kit distributed to the schools in the form of CDs which include information and trivia on biotechnology, animations explaining processes and procedures in a molecular biology laboratory, electronic crosswords and interactive molecular graphics visualization interface for virtually exploring a DNA molecule. 
purposes. Participants are taken through the steps of PCR and RFLP, and how these methods can be used for genetic differentiation and forensics. With these hands on experiences, it is hoped that the participants can better relate to material that they have read or will read about and therefore instil a better understanding of what the technology is all about.

The games session consists of three games 'Liku-Liku DNA' (translated to imply 'Journeying through the bends of the DNA helix'), 'Dolly - the board game' (a game developed by Sheffield Hallam University and the British Council, with the Malay language content added in by Universiti Kebangsaan Malaysia and an interactive role playing game using dice (Figure 3). The multimedia exploration session consists of an interactive MacromediaTM Flash and web interface with integrated molecular visualization tools enabled using the MDLChime web browser plug-in (http://www.mdlchime.com/) (Figure 4). These games, animations and interactive multimedia applications were designed to enable comprehension of real-world applications of recombinant DNA technology, implications of the genomics / post genomics era and also includes some issues to stimulate the thinking of the participants such as those regarding ethics of cloning (human and animals) and genetically modified organisms. The participants are then given a quiz to enable them to apply the multimedia content which they have gone through. These exercises were formulated to instil in the participants a responsible and thinking attitude towards biotechnology developments and at the same time provide them with the basic knowledge as the basis to make educated decisions about biotechnology.

\section{PROGRAM PROLIFERATION}

The methodology which was employed to proliferate this program was a simple momentum based approach. The initial schools for this program were approached and presented with this idea either directly or via the district education department. The initial plan aimed to have a program carried out at least at a few schools in every state in Malaysia (of which there are 14 including the Federal territories). As the ball started rolling, schools and education district departments which had heard of the program began volunteering for participation. Currently the program is in its fourth year of operations and has reached out to 563 schools, numbering approximately 18000 students. This makes the number of schools reached by this program at about $30 \%$ of the total number of Malaysian high schools which is a marked increase compared to the original 17 schools numbering 1050 students in the first year.

As mentioned earlier, the way the program is conducted is similar to a travelling road show. The bulk of the facilitators come from the ranks of postgraduate students and research assistants while the core lecturers and speakers are drawn from a pool of university academics or senior scientists attached to research institutes. While the main target of the program was high school students, the program participants also included the science teachers of the participating schools. They are the ones who shoulder the direct responsibility to inform their students in a sound way of the scientific and technical aspects of biotechnology and to qualify the students as the decision makers of the future to deal in a reasoned way with the chances and risks of biotechnology (Harms, 2002). We see this as an important aspect in proliferating and sustaining the program. The inclusion of the teachers is hoped to be able to further propagate the program to students of future batches. While there is no written policy or rule about repeat visits to the same school, this would not serve the bigger purpose of reaching out to as many schools as possible. While the logistics and some personnel support will be offered, it is hoped that the respective schools may in the future conduct their own sustained sessions. We view this sustained proliferation as an important aspect of the program.

Alternatively, plans are in place to increase the numbers of teachers trained as the program facilitators. Teachers who are interested in the continuity of this program can take part in training workshops which train them as facilitators. As most of the teachers involve are either biology or chemistry graduates, there is only a need to update them on the current state of the art for biotechnology. This is hoped to keep them abreast about emerging fields such as genomics, bioinformatics, proteomics and will enable them to carry up to date discussions with their students. This teacher training program has been integrated into the existing program starting 2003 with the first session conducted during the annual school holidays. In this way, we hope to wean the program of its high dependent on postgraduate students and research assistants. With the schools' science teachers in place to act as facilitators, what is required by the central program is simply to provide the logistics and core personnel to conduct the lectures and talks. The hands on sessions can then be carried out by the science teachers themselves. Additionally a web portal has been set up to provide further information as well as to support the program by providing electronic content and a forum for further discussion of the program's participants. We hope to make the portal a truly integral part of the program by including proposal submissions as well as make it a mechanism of past participating schools to acquire logistics support to self sustain their own biotechnology awareness efforts to their students (http://www.nbbnet.gov.my/pintarbiotek/).

\section{CONCLUSIONS AND FUTURE DIRECTIONS}

It can be said that this biotechnology awareness program to 
Malaysian high schools started out as an experimental program to gauge and formulate outreach capabilities to facilitate capacity building and public education. We are pleased to note however, that this program can now be integrated as part and parcel of the Malaysian national biotechnology program to develop human resource by approaching capacity building from the grassroots level. However, we hope that in an indirect way, this program has reached out to and benefited more than the 18000 students we've stated. By embarking on this program, we hope that the decisions of the current and future generations to accept or reject new developments in biotechnology will be based upon a solid basic understanding of biotechnology and not as the result of induced hype, biasness or xenophobia. Amongst other similarly tailored programs which is hoped to be put in place, are programs derived from this one, which is targeted at policy makers and other professionals (medical, legal, engineering, and finance professionals). It is hoped, that while we are investing in the future, by educating the Malaysian youths about biotechnology, we also realize the necessity to address current capacity building needs by harnessing the capabilities of the present workforce towards the development of biotechnology in Malaysia. At the same time, we realize that a program which we hope is extensive and is able to provide first hand experience to the participants is an expensive endeavour. However, the financial burden can be shared by government as well as corporate bodies and can be viewed as a worthwhile investment towards building a healthy and balanced biotechnology research and industry environment in Malaysia.

\section{ACKNOWLEDGEMENTS}

The authors thank the Ministry of Science, Technology and Innovation, Malaysia for the funding and support to make this program a reality. We would also like to acknowledge the Ministry of Education, Malaysia as well as all the institutions, postgraduates and educators who have put in the sincere effort towards successfully realizing this program. The material support and sponsorships from the British Council are also duly acknowledged.

\section{REFERENCES}

DA SILVA, E.J. Biotechnology, developing countries and globalization. World Journal of Microbiology and Biotechnology, 1998, vol.14, p.463-486.

HARMS, Ute. Biotechnology education in schools. Electronic Journal of Biotechnology [online]. 15 December 2002, vol. 5, no 3 [cited 20 March 2004]. Available from the internet: http://www.ejbiotechnology.info/content/vol5/issue3/teachi ng/01/index.html. ISSN 07173458. 